\title{
Avaliação do curso de formação de professores no contexto da Educação a Distância ${ }^{1}$
}

\section{Teachers' training course assessment in the context of Distance Education}

\author{
Veronica Branco ${ }^{2}$ \\ Sonia Maria Chaves Haracemiv ${ }^{2}$
}

\begin{abstract}
RESUMO
O estudo apresenta a avaliação do Curso de Pedagogia à distância da Universidade Federal do Paraná, sob a ótica dos protagonistas. O curso foi realizado em parceria entre a Universidade Federal do Paraná (UFPR) e a Universidade Aberta do Brasil. Esta pesquisa procurou estudar quatro categorias: atividades-tarefas; materiais de ensino; infraestrutura da UFPR, do Polo e do lugar de estudos do aluno; e tutoria, desde o início do trabalho em seis classes. O objetivo da prática avaliativo-diagnóstica, no curso de formação de professores, foi no sentido de repensar novos encaminhamentos pedagógicos, frente à avaliação em relação às tecnologias do sistema de comunicação da Plataforma do Ambiente Virtual de Aprendizagem, das mídias interativas, dos materiais impressos, bem como as utilizadas nos momentos presenciais. Ancorada nos pressupostos da pesquisa-ação, a investigação buscou, a partir da análise dos dados levantados, atender às demandas, na compreensão da avaliação do ensino e aprendizagem no contexto da Educação a Distância, numa perspectiva de avaliação-formativa, pois os resultados obtidos durante a investigação se tornaram, continuadamente, objetos de estudo, ação e reflexão.
\end{abstract}

Palavras-chave: formação de professores a distância; avaliação diagnóstico-formativa; práticas avaliativas na Educação a Distância.

DOI: $10.1590 / 0104-4060.42113$

1 Pesquisa com fomento da Coordenação de Aperfeiçoamento de Pessoal de Nível Superior (CAPES) / Universidade Aberta do Brasil (UAB).

2 Universidade Federal do Paraná, Setor de Educação, Departamento de Teoria e Prática de Ensino. Programa de Pós-Graduação em Educação, Linha Cognição e Aprendizagem, Mestrado Profissional. Curitiba, Paraná, Brasil. Rua General Carneiro, $\mathrm{n}^{\circ}$ 460, $5^{\circ}$ andar. Centro. CEP: 80060150.E-mails: sharacemiv@ufpr.br; veronica_branco@hotmail.com 


\begin{abstract}
This study presents an evaluation of the undergraduate distance learning Pedagogy Course, offered by Universidade Federal do Paraná (UFPR), the Federal University of Paraná, from the perspective of the protagonists. The Course is held in a partnership between UFPR and the Open University of Brazil. This survey sought to study four categories: tasks-activities, teaching materials, the UFPR, the Polo and the place of students' studies infrastructure; also tutoring, from the beginning of work in six classes. The purpose of this evaluative-diagnostic practice regarding a teacher training course was to rethink new educational referrals related to the Virtual Learning Environment Platforms communication technologies system, interactive media, printed materials as well as those used in classroom learning. Anchored in research action assumptions and based on the data analysis, this search sought to meet the demands in understanding the assessment of teaching and learning in the context of Distance Education, with a view to formative assessment, since the results obtained during the investigation became, continuously, objects of study, action and reflection.
\end{abstract}

Keywords: teachers' training distance learning; diagnostic-formative assessment; assessment practices in Distance Education.

\title{
Introdução
}

Entre os novos rumos da educação encontra-se a Educação a Distância (EaD), “[...] uma modalidade não tradicional, típica da era industrial e tecnológica, cobrindo distintas formas de ensino-aprendizagem, dispondo de métodos, técnicas e recursos, postos à disposição da sociedade". (PRETI, 1996, p. 19). $\mathrm{O}$ desenvolvimento das diferentes tecnologias, desde o material impresso, passando pelo rádio e pela televisão, até chegar aos computadores, às modernas técnicas de comunicação conjugadas às ciências cognitivas transformaram a EaD em campo vastíssimo de experimentação de novos métodos e técnicas de aprendizagem. (PRETI, 2005³ apud GIOLLO, 2008, p. 1227).

Essas diferentes metodologias, técnicas e materiais de apoio têm trazido dimensões importantes para discussões sobre a formação do professor na modalidade de $\mathrm{EaD}$, sobretudo, para aqueles que irão atuar na Educação Básica, frente às realidades socioculturais nas quais se situam as realidades educativas,

3 PRETI, O. (Org.). Educação a Distância: sobre discursos e práticas. Brasília, DF: Liber Livro, 2005. 
que são dinâmicas, se expressam em diferentes aspectos da vida social, política, cultural e econômica. O impacto das tecnologias da informação e comunicação sobre os processos de ensino e de aprendizagem justifica a necessidade de atualizar o conjunto de decisões pedagógicas de avaliação, acompanhamento e de intervenção educativa. Assim sendo, é preciso repensar o processo de formação docente, para que:

[...] a educação esteja em seu conteúdo, em seus programas e em seus métodos, adaptada ao fim que se persegue: permitir ao homem chegar a ser sujeito, construir-se como pessoa, transformar o mundo e estabelecer com os outros homens relações de reciprocidade, fazer a cultura e a história... (FREIRE, 1979, p. 42).

Essa nova concepção de sociedade exige repensar um novo conceito de escola e de seu papel social, exigindo que a educação seja um processo de humanização, com caráter problematizador e dialógico, visto que "[...] se impõe como caminho pelo qual os homens ganham significação enquanto homens". (FREIRE, 1983, p. 93). Para acompanhar as transformações trazidas pelas tecnologias digitais, é necessário adaptar-se ao novo e às possibilidades oferecidas pelos recursos tecnológicos, exigindo pesquisas sobre os processos de "avaliação de ensino e aprendizagem na modalidade educacional à distância". (OLIVEIRA, 2011, p. 56, grifo nosso).

A partir da Lei de Diretrizes e Bases da Educação Nacional (LDBEN), $\mathrm{n}^{\circ}$ 9.394, de 20 de dezembro de 1996, Art. 80, a Educação a Distância foi regulamentada no Brasil como política educacional. (BRASIL, 1996). Nas Diretrizes apresentadas pelo Decreto $\mathrm{n}^{0} 5.622$, de 19 de dezembro de 2005, publicado no Diário Oficial da União (DOU), de 20 de dezembro de 2005, a EaD ficou caracterizada, no Art. $1^{\circ}$, como "[...] modalidade educacional na qual a mediação didático-pedagógica nos processos de ensino e aprendizagem ocorre com a utilização de meios e tecnologias de informação e comunicação, com estudantes e professores desenvolvendo atividades educativas em lugares ou tempos diversos", sendo que, no $\S 1^{\circ}$, do referido Decreto, estão postas referências à organização da $\mathrm{EaD}$ "[...] segundo metodologia, gestão e avaliação peculiares, para as quais deverá estar prevista a obrigatoriedade da avaliação em momentos presenciais [...]". (BRASIL, 2005).

No Decreto $\mathrm{n}^{\circ} 5.622$, a normatização do processo avaliativo foi mantida, pois já havia sido definido pela Portaria Ministerial $n^{\circ} 4.361$, de 2004, que estabelecia, no Art. $1^{\circ}$, a obrigatoriedade de momentos presenciais não só para a 
avaliação dos estudantes, mas também para outras atividades, como exigência de presencialidade para a avaliação, afirmando que os resultados dos exames presenciais deveriam prevalecer sobre os demais resultados. (BRASIL, 2005). Para os educadores essa normatização está posta em direção contrária à avaliação processual, pois todas as atividades constitutivas dos processos de ensino e aprendizagem são consideradas menos importantes.

Pelo Decreto ${ }^{\circ} 5.800$, de 08 de junho de 2006, o Sistema da Universidade Aberta do Brasil (UAB) foi regulamentado "[...] voltado para o desenvolvimento da modalidade de educação à distância, com a finalidade de expandir e interiorizar a oferta de cursos e programas de educação superior no país", e dentre outros objetivos, "[...] oferecer, prioritariamente, cursos de licenciatura e de formação inicial e continuada de professores da Educação Básica", com implantação de Polos de apoio presencial, com infraestrutura tecnológica, com acesso às Tecnologias de Informação e Comunicação (TIC), sistemas multimídias ligados à internet, banda larga. A coordenação, implantação, acompanhamento, supervisão e a avaliação dos cursos EAD, segundo o Art. $7^{\circ}$ do referido Decreto, fica a cargo do Sistema UAB. (BRASIL, 2006).

Frente às políticas públicas constata-se que os órgãos públicos, com a participação de várias instâncias sociais, foram definindo parâmetros avaliativos de qualidade para a modalidade de Educação a Distância de forma que a avaliação dos cursos das universidades em parceria com a UAB:

[...] passa a ser caracterizado por qualidade que traz em sua definição competência e excelência, cujo critério, é o atendimento às necessidades de modernização da economia e desenvolvimento social. Muitas vezes, para atender a essas necessidades, as políticas públicas fazem opções de atender o quantitativo educacional ao qualitativo, mesmo que se construa um discurso em documentos oficiais de forma distinta. (CHAUÍ, 2003 apud SANTOS, 2011, p. 4).

Considerando a afirmação da autora, a coordenação do curso pensou numa avaliação que levasse em conta o prescrito nos documentos oficiais, o Projeto Político-Pedagógico do Curso de Pedagogia - Magistério da Educação Infantil e Anos Iniciais do Ensino Fundamental, considerando as seguintes dimensões: o ensino ministrado a distância (on-line) e presencial (aulas e encontros no

4 CHAUÍ, M. A universidade pública sob nova perspectiva. Rev. Bras. Educ., Rio de Janeiro, n. 24 , set./dez. 2003. 
Polo), os meios utilizados quanto à adequação à aprendizagem dos envolvidos, em diferentes espaços e tempos de ensinar e aprender, bem como a estrutura e o funcionamento do sistema de comunicação das tecnologias utilizadas considerando a estrutura física e pedagógica da Plataforma Moodle, materiais impressos e mídias interativas, com o objetivo de avaliar o desempenho institucional das instâncias responsáveis pelas etapas do projeto Universidade Federal do Paraná (UFPR)/UAB/Polo/Coordenação Institucional de Programas de Educação a Distância (CIPEAD), sendo esta última responsável pela gestão de todos os cursos a distância ofertados na UFPR.

A pesquisa tem o objetivo de realizar uma avaliação que priorize os aspectos qualitativos, muitas vezes colocados pelas exigências legais, dificultando o trabalho docente no campo da avaliação em Educação a Distância, como também a construção de uma nova cultura avaliativa, que possibilite a mudança, a partir da criação de uma nova cultura, pois “[...] o sistema educacional está profundamente marcado pela necessidade de criação de uma nova cultura sobre avaliação que ultrapasse os limites da técnica e incorpore em sua dinâmica a dimensão ética". (ESTEBAN, 2008, p. 8).

Essa investigação é caracterizada como pesquisa-ação, pois, na medida em que a avaliação da intervenção dos professores e tutores vai sendo avaliada pelos educandos, nos momentos presenciais e a distância, a mediação e a percepção de cada um sobre si e sobre o processo possibilitam a todos reconstruir-se como sujeito cognoscente. (FREIRE, 1997, p. 28).

\section{Procedimentos de pesquisa}

Levando em consideração a necessidade de repensar continuamente o que a realidade escolar atual exige e o que a realidade das instituições formadoras vem oferecendo, o objeto de investigação deste trabalho foi delineado: a avaliação do Curso de Pedagogia - Magistério da Educação Infantil e Anos Iniciais do Ensino Fundamental, na parceria UFPR e UAB, investigação que buscou na pesquisa-ação a metodologia de aprender, superar, construir-se como educador, nos imbricados caminhos, frente à modalidade de ensino a distância, junto aos educandos, com rigorosidade metódica e compromisso com a criticidade, pois a compreensão humana na educação impõe ao educador a dificuldade de compreender o vivido e o observado sobre as condições de pertencimento e participação. (FREIRE, 1997, p. 29). 
Participaram da pesquisa de avaliação do Curso de Pedagogia EaD da UFPR, no período de 2009 a 2010, duas coordenadoras, a pedagógica e a de tutoria, 10 tutoras presenciais e 10 tutoras a distância, sendo duas para cada Polo, 250 alunos das seis turmas dos cinco Polos, sendo que o de Colombo tinha duas turmas, e os demais com uma turma, Rio Negro, Palmeiras e Nova Tebas, no estado do Paraná, e Embú das Artes, em São Paulo.

Para tanto, foi elaborado um instrumento de pesquisa, visando diagnosticar, junto aos envolvidos, as dificuldades a serem superadas, a partir dos diferentes olhares, na realização de um trabalho em parceria, compromissado com os princípios pedagógicos de formação docente. (ÁLVARO MÉNDEZ, 2002, p. 16). O instrumento utilizado foi o questionário eletrônico, disponibilizado na Plataforma Moodle da CIPEAD/UFPR, constituído em quatro categorias, sendo: Atividades-Tarefas, Material Didático, Infraestrutura e Tutoria. Cada categoria foi subdividida em subcategorias, sendo que em cada uma delas foram apresentadas situações descritas, sobre as quais os envolvidos deveriam apontar o seu grau de atendimento, em: ótimo, bom, regular ou sofrível, aquele que considerasse caracterizar o processo de ensino e aprendizagem naquele momento.

A pesquisa considerou os aspectos qualitativos do processo de avaliação, com o objetivo de redimensionar o fazer pedagógico, numa dinâmica de reflexão-ação, de modo que as práticas pedagógicas da $\mathrm{EaD}$ fossem sendo repensadas e auxiliassem os envolvidos nos percursos de ensino e aprendizagem, de forma contínua, com o objetivo de melhorá-la, num processo formativo.

\section{Procedimentos de pesquisa na avaliação do Curso de Pedagogia EaD}

Esta pesquisa-ação numa perspectiva de avaliação formativa partiu do pressuposto de que na ação educativa existe uma concepção de ensino e de aprendizagem que se efetiva na medida em que todos os envolvidos agem e refletem, coletivamente, no desenvolvimento do trabalho pedagógico, buscando encaminhamentos para os problemas diagnosticados nas avaliações.

Partindo dos pressupostos da pesquisa-ação e de que as interpretações, compreensões e estranhamentos das ações configuradas aos olhos da população pesquisada parecem, para alguns, ações óbvias, quanto ao grau de atendimento frente às dimensões contextuais, e para outros as ações precisam ser problematizadas, esta pesquisa foi desenvolvida com o objetivo de que a análise poderia ser ampliada para além da crítica-reflexiva, considerando que esse processo de compreensão compartilhada possibilita a aproximação do "[...] 
empírico, o teórico e o subjetivo no âmbito da investigação na comunidade com seu envolvimento profissional e ético". (FREIRE, $1997^{5}$ apud JUNIOR; ROCHA, 2011, p. 10), fazendo com que a subjetividade implícita no trabalho docente se revelasse pela pesquisa, a partir de leituras e experiências trocadas nas práticas e estudos dos fatos observados, diagnosticados e interpretados no cotidiano escolar, configurando uma avaliação formativa. (PORTO; NEVES; MACHADO, 2012, p. 6).

Considerando a fala dos autores, esta pesquisa no contexto da Educação a Distância, com momentos on-line e presenciais de ensino e aprendizagem, com utilização das TICs, “[...] que oferecem diversas formas de interação, seja com conteúdos informativos, seja através da interação entre os sujeitos" (OLIVEIRA, 2011, p. 45), foi sendo efetivada, a partir da análise dos resultados da avaliação, possibilitando, na medida do possível, intervir na prática docente, de forma a atender às demandas apontadas na avaliação das categorias investigadas.

\section{Avaliações das Tarefas on-line e presenciais: ensino e aprendizagem em espaços e tempos diferentes}

Os procedimentos de avaliação descritos no Projeto Político-Pedagógico do Curso de Pedagogia - Magistério da Educação Infantil e Anos Iniciais do Ensino Fundamental normatizam que:

Em cada disciplina e nas suas respectivas Unidades Didáticas há uma série de atividades avaliativas propostas tais como: a) atividades e exercícios sobre o(s) texto(s) selecionado(s); b) atividades complementares: pesquisa, produção de texto, etc.; c) leituras complementares indicadas; d) exercícios de autoavaliação da Unidade Didática. e) Participação em Fóruns on-line. Estas atividades irão compondo um processo de acompanhamento e avaliação do processo de aprendizagem do aluno. (UFPR/ PPP, 2009, p. 39).

As atividades propostas aos alunos em cada disciplina no Ambiente Virtual de Aprendizagem (AVA) têm por objetivo a aprendizagem do conteúdo

5 FREIRE, P. Pedagogia da autonomia: saberes necessários à prática educativa. Rio de Janeiro: Paz e Terra, 1997. 
estruturante da disciplina, o desenvolvimento da autonomia de aprendizagem em cumprimento à carga horária a distância, que deve ser de no mínimo $75 \%$, tanto quanto à carga horária presencial. Assim, quando as atividades não são postadas no prazo determinado para cada disciplina, isso demonstra que o aluno não está estudando e fazendo uso das ferramentas de aprendizagens criadas para a Educação a Distância, não cumprindo com os $75 \%$ da carga horária de estudo à distância, e, assim, não pode fazer a prova da disciplina. A somatória dos pontos obtidos na avaliação dessas atividades tem peso 4 (quatro). A avaliação da disciplina, de acordo com a legislação em vigor para a EaD (BRASIL, 2005), deverá se dar com exame presencial, por escrito e sem consulta, ao final de cada disciplina terá peso 6 (seis). (PPP/UFPR, 2009, p. 40).

Nesta pesquisa essa normatização foi questionada em relação à avaliação das atividades, na categoria Atividades-Tarefas e subcategorias, agrupadas segundo os eixos tempo e aprendizagem. Cada subcategoria consistia numa afirmação que deveria ser completada com um dos conceitos: ótimo, bom, regular ou sofrivel, pelos protagonistas educandos, quanto ao grau de atendimento de cada uma delas, frente ao sentido e vivido por eles na realização das atividades propostas para cada disciplina.

Para a análise dos resultados da avaliação na referida categoria participaram seis educandos, como representantes de turma, coordenadoras, tutores presenciais e a distância, professores conteudista e formadores. Para leitura e sistematização dos resultados das avaliações, as afirmações foram reescritas da seguinte forma: O tempo para realização das atividades-tarefas, a organização do tempo de estudo determinado por você e a quantidade das atividades-tarefas possibilitaram uma aprendizagem...?

Para os acadêmicos do Curso de Pedagogia, o tempo para a realização das atividades-tarefas foi regular em algumas disciplinas, e sofrível para outras, principalmente para as disciplinas do bloco de Fundamentação Teórica, pois, segundo eles, a complexidade dos temas, que exigia muita leitura e interpretação, bem como a quantidade de atividades de produção de texto, comprometia a aprendizagem, sendo que muitas vezes as atividades foram devolvidas por estarem incompletas e/ou não postadas em tempo no AVA. Vale ressaltar que muitos licenciandos, nas primeiras disciplinas do curso, não puderam fazer as provas regulares porque não realizaram o mínimo exigido de $75 \%$ das atividades postadas na Plataforma Moodle/AVA. Não conseguiram postar as atividades nas três primeiras semanas do módulo da disciplina ministrada em quatro semanas. Isso pode ser justificado porque depois das três semanas uma nova disciplina se iniciava e novas tarefas deveriam ser cumpridas, sendo que o acúmulo delas poderia prejudicar o rendimento final. (PPP/UFPR, 2009. p. 40). Essa questão foi debatida intensamente, pois, segundo Santos (2006): 
[...] ferramentas que possibilitem o controle da participação do aluno e da assiduidade na entrega das tarefas poderiam ser úteis para a avaliação da aprendizagem, mas não é suficiente para o professor identificar os avanços e dificuldades dos alunos em termos de aprendizagem dos assuntos. (SANTOS, 2006, p. 146).

Assim sendo, “[...] a idéia de que a tecnologia por si só não consegue modificar a prática avaliativa, por mais recursos que ela ofereça, constitui-se em ferramenta para ser utilizada como meio, e não como fim em si mesmo". (SANTOS, 2006, p. 108).

A partir da avaliação houve um repensar coletivo, envolvendo professores, tutores, representantes de turma, coordenação pedagógica e de tutoria, tendo como pressuposto uma avaliação formativa de que é "[...] imprescindível a mediação do professor para que o processo de avaliação ocorra na perspectiva formativa, processual e reguladora das aprendizagens". (SANTOS, 2006, p. 109).

Frente ao processo avaliativo das atividades houve uma adequação do intervalo prefixado de tempo para leituras indicadas nos materiais, tempo das aulas e encontros presenciais no Polo, levando-se em conta o perfil do educando do Curso de Pedagogia, indivíduo geralmente maduro, com uma história de vida cheia de experiências, conhecimentos, capacidades, hábitos, atitudes, condutas e interesses no seu processo de formação. Os períodos escolares, que condicionavam a prática educativa a distância, o planejamento e o currículo, foram repensados, pois não estavam levando em conta a atividade cognoscitiva do sujeito aprendiz. (ARETIO, 2001). Muitos deles não deixavam de fazer as atividades porque simplesmente havia acabado o tempo na Plataforma, apresentavam interesse em aprender, em vencer dificuldades, como as lacunas do Ensino Médio, habilidades com as tecnologias, sendo que muitos deles admitiram que não tinham computador em casa e não sabiam lidar com as ferramentas tecnológicas, o que foi um desafio. $\mathrm{Na} \mathrm{EaD}$, o uso da tecnologia e da mídia vem configurando diferentes formas de se lidar com o tempo e o espaço, bem como "[...] as padronizações dos mesmos e as formas como oportunizam a formação necessária ao exercício da profissão, principalmente para aqueles que não se enquadram nos padrões de tempo e espaço colocados pela escola". (POSSARI, 2005, p. 92).

Assim sendo, os protagonistas repensaram a flexibilidade e variedade nas relações espaços-temporais, nos cronogramas e nas atividades propostas na EaD, viabilizando ao aluno explorar suas percepções, experiências, atitudes, para aprender e construir conhecimentos tendo como parâmetro as suas possibilidades de espaço e tempo. Os sistemas de ensino a distância são estabelecidos geralmente para atender a uma população adulta que aprende e se manifesta de 
maneira diferente das crianças, adolescentes ou jovens. Nesse sentido, foi um desafio a vencer, assumir novas posturas diante dessa modalidade de ensino-aprendizagem, estabelecendo novas relações mediadas por diferentes formas de interação. Isso vem sendo verificado na elaboração do material, de orientações quanto ao fazer pedagógico em sala de aula, física e virtual, como também na elaboração das atividades e avaliações. Já é possível perceber, numa dimensão ainda que diminuta, uma autonomia dos sujeitos, professores, tutores, alunos e coordenação frente à avaliação, sendo que ela

[...] deixa de significar fazer um julgamento sobre a sua aprendizagem, para servir como momento capaz de revelar o que o aluno já sabe e os caminhos que percorreu para alcançar o conhecimento demonstrado, seu processo de construção do conhecimento, o que o aluno não sabe e o caminho que deve percorrer para vir, a saber, o que é potencialmente revelado em seu processo, suas possibilidades de avanço e suas necessidades para a superação, sempre transitória, do não saber, possa ocorrer. (ESTEBAN, 2008, p. 19).

\section{Avaliando o Material Didático}

Ter como elemento indicador da aprendizagem a avaliação do material didático exige pensar numa perspectiva de avaliação formativa, pois “[...] essa avaliação possibilita obter informações sobre a aprendizagem dos educandos, contribuindo com seu desenvolvimento durante todo o processo". (PERRENOUD, 1999, p. 103). O material didático-pedagógico elaborado deve ter como objetivo o processo de construção do conhecimento, e na EaD, o educador precisa redimensionar os aspectos da prática docente, do desenvolvimento no sentido de um projeto educativo, utilizando-se de materiais didáticos impressos e virtuais. (VERSUTI, 2007). Nesse sentido, a elaboração do material didático da EaD exige do professor a preocupação com três elementos didático-pedagógicos: objetivos e conteúdos propostos no programa da disciplina, linguagem nas orientações metodológicas e otimização dos recursos no ambiente virtual, de forma que nenhum desses elementos venha comprometer a ação pedagógica desejada. (VERSUTI, 2007).

Dessa forma, na análise da avaliação, na categoria Material Didático, três elementos foram considerados, sendo que as subcategorias foram agrupadas, reescritas e analisadas segundo a questão da relevância do Material Didático 
impresso, bem como os apresentados no Ambiente Virtual de Aprendizagem, Plataforma Moodle, quanto: às relações entre os objetivos e conteúdos propostos no programa da disciplina, a densidade teórica e aprofundamento dos conteúdos abordados no material e as referências bibliográficas, redação dos textos contidos no material e dos recomendados nos links, bem como as orientações metodológicas na organização do conteúdo, diagramação e imagens, possibilitaram a compreensão das disciplinas e a efetiva aprendizagem?

Observou-se que o Material Didático foi avaliado com grau sofrível a relação aos objetivos propostos em algumas disciplinas, frente à profundidade e densidade dos conteúdos. A discussão sobre a teoria da extensão e densidade do conhecimento não foi desarticulada da possibilidade da construção e produção do conhecimento pelo educando, ficando relacionada à questão do ensinar, não transferindo conhecimento com linguagem elaborada, mas de forma que $o$ "[...] conhecimento precisa ser apreendido pelo educando, nas suas razões de ser-ontológica, política, ética, epistemológica, pedagógica, e precisa ser constantemente testemunhado, vivido" (FREIRE, 1997, p. 52), acrescentando que:

[...] as razões ontológicas, epistemológicas e políticas [...] discurso sobre a Teoria deve ser o exemplo concreto, prático, da teoria. [...] falar da construção do conhecimento, criticando a sua extensão, já devo estar envolvido nela, e nela, a construção, estar envolvendo os alunos. Fora disso, me emaranho na rede das contradições em que meu testemunho, inautêntico, perde eficácia. (FREIRE, 1997, p. 52-53).

O afirmado pelo autor faz sentido para a avaliação dos acadêmicos, quanto aos textos recomendados nos links, na sessão "saiba mais", que além de ser de difícil acesso, pois em alguns Polos, principalmente em Nova Tebas-PR, a conexão on-line era péssima, nem celular muitas vezes pegava, apresentavam termos na redação que exigiam outras leituras, e os conteúdos muitas vezes se distanciavam dos objetivos, não possibilitando a compreensão e a efetiva aprendizagem. Quando necessário uma pesquisa bibliográfica, o acervo dos Polos deixa muito a desejar, sendo que os livros que seriam enviados pelo Ministério da Educação (MEC), que foram indicados pela coordenação, em atendimento às indicações dos professores das disciplinas, até o ano de 2011, quando da saída da coordenação das autoras desta pesquisa, não haviam sido disponibilizados. Dessa forma, a única fonte de pesquisa seria o acesso aos ambientes on-line de aprendizagem, que além das informações disponibilizadas, segundo Oliveira (2011), esses recursos possibilitam a interlocução entre os sujeitos, o que favorece a aprendizagem, uma vez que eles: 
[...] permitem ao aprendiz decidir o rumo da sua navegação pelos diversos links disponíveis, revelando um pensar não linear, de modo que os conhecimentos se reorganizam conforme os objetivos ou contextos, uma forma de trabalho que geralmente não tem espaço na educação convencional. (SANTOS, 2006, p. 90).

As duas turmas do Polo de Colombo avaliaram como regular as subcategorias em questão, pois, de certa forma, são privilegiadas. O Polo fica situado na região metropolitana de Curitiba, próximo à UFPR, onde a Biblioteca do Setor de Humanas é uma das maiores do estado na área de Educação. Também, por essa aproximação geográfica à Universidade, os acadêmicos procuram os professores das disciplinas, mediados pelos tutores, possibilitando orientações metodológicas na organização e compreensão dos conteúdos, mesmo assim, os licenciandos ainda consideraram regular a aprendizagem, pois os outros elementos didáticos, apresentados nas subcategorias, a comprometiam.

Dessa forma, qualquer ação educativa comprometida com a real aprendizagem dos sujeitos deve estar baseada no diálogo, na troca, na participação e na colaboração, portanto, os elementos da ação didático-pedagógica a distância e/ou presencial frente às disposições informacionais e comunicacionais do computador on-line não podem estar baseados numa pedagogia da transmissão de conhecimento. Devem estar baseados na "[...] liberdade de autoria, multiplicidade de acessos e de conexões, diálogo, troca de informações e de opiniões, participação, intervenção e autoria colaborativa são princípios essenciais em educação cidadã". (SILVA; HOFFMANN; ESTEBAN, 2006, p. 27).

Aos protagonistas, principalmente os professores conteudista (autores dos materiais didáticos) e/ou os formadores (professores docentes das disciplinas), frente à avaliação da referida categoria, foi recomendado "[...] reflexões no sentido de avaliar e ajustar as ações didáticas de forma que as intervenções pedagógicas e as situações didáticas de ensino dos conteúdos propostos enfatizassem as aprendizagens dos mesmos". (PERRENOUD, 1999, p. 89).

\section{Avaliando a Infraestrutura da Universidade e do Polo}

Neste trabalho a categoria Infraestrutura foi avaliada pelos protagonistas objetivando revelar os espaços de ensino e aprendizagem da Universidade e dos Polos, buscando repensá-los em todo o contexto social, levando em conta, no 
caso em questão, os espaços físicos e virtuais, onde o ensino e aprendizagem são midiatizados pelos espaços, sujeitos e tempos diferentes, em condições estruturais que devem estar "[...] para além da funcionalidade econômica e prática dos objetos técnicos, entra em jogo a trama concreta da vida cotidiana". (CARDOSO, 1999, p. 45).

$\mathrm{Na}$ avaliação da categoria Infraestrutura, tanto a oferecida pela Universidade como a do Polo de apoio foram questionadas quanto às condições e funcionalidade dos espaços físicos, como a sala de aula, biblioteca, salas de apoio tecnológico e pedagógico para atendimento dos tutores presenciais, salas para secretaria acadêmica, coordenação do Polo. Quanto aos recursos tecnológicos, foram consideradas as condições de implantação e funcionamento dos laboratórios pedagógicos com computadores, conexões de internet, Plataforma Moodle, kit de webconferência com videoconferência e Skype, projetor de multimídia, impressora e linha telefônica. Em tempo, vale ressaltar que:

A infraestrutura física e tecnológica do polo de apoio presencial da UAB é de responsabilidade do mantenedor, que deve garantir o espaço físico, com a infraestrutura necessária para instalação e manutenção dos equipamentos. É vedada a utilização das estruturas físicas e tecnológicas em finalidades que não sejam a de apoiar o processo ensino-aprendizagem dos alunos vinculados ao Polo da UAB. Os Convênios com o FNDE visam a liberação de recursos para reforma, ampliação e compra de equipamentos. (BRASIL, 2010, p. 16).

$\mathrm{Na}$ avaliação ficou evidenciado que as condições de infraestrutura, tanto da Universidade quanto dos Polos, estavam de regular a sofrível, não contribuindo plenamente na qualidade do ensino e da aprendizagem, uma vez que o acesso precário à internet ou a (in)disponibilidade para utilização de outros aparatos tecnológicos interferiam na comunicação institucional entre professores, tutores e licenciandos. Em todos os Polos muitos alunos só tinham acesso ao material impresso, telefone e correio, sendo o Polo o único espaço no município onde recorriam para digitar e postar as tarefas.

Segundo todos os protagonistas, de nada adianta ter o aparato tecnológico se muitas vezes não há o apoio humano presente, pois as "máquinas encontram-se envolvidas pela trama dos investimentos subjetivos que as elevam ao nível de presença sociocultural, transcendendo o destino de meros objetos destituídos de qualquer outro significado". (CARDOSO, 1999, p. 45). A avaliação revelou que para um efetivo acompanhamento do processo de aprendizagem na Edu- 
cação a Distância, ela deve estar baseada na construção coletiva de pessoas em ambientes adequados e utilização de ferramentas tecnológicas de comunicação, como os fóruns, e-mail, blogs, listas de discussão, Wiki, além de tantas outras interfaces que possibilitam o diálogo, o debate e a negociação em diferentes espaços. (SILVA; HOFFMANN; ESTEBAN, 2006).

O recado dado na avaliação da categoria Infraestrutura é de que para alcançar a plena satisfação no desempenho das atividades humanas educacionais todos os envolvidos no processo de ensino e aprendizagem devem usufruir dos recursos de qualquer ambiente, dia e horário, ou seja, de todo potencial físico e tecnológico da Universidade e/ou do Polo. (SILVA et al., 2010).

\section{Avaliação dos Tutores a distância e presencial}

$\mathrm{Na}$ avaliação da categoria Tutores as subcategorias foram organizadas de forma que revelassem como os protagonistas dimensionam as ações que cada tutor desempenha em seu espaço de atuação, isto é, a distância na UFPR atendendo via on-line, e presencial no Polo. Para análise dos resultados da avaliação da referida categoria, as subcategorias foram organizadas em dois eixos, quanto à Relação Educador \& Educando e Ações Didático-Pedagógicas de ensino e aprendizagem. Essa organização pode ser conferida no Quadro I. Cabe ressaltar que as subcategorias foram definidas pelo vivido e sentido no desenvolvimento do curso, pela insatisfação dos tutores UFPR e dos Polos, nas relações junto aos professores formadores, docentes das disciplinas. Na medida em que as análises dos dados se processavam, os conflitos, muitos deles diagnosticados no decorrer do curso se revelavam, principalmente frente às atribuições inerentes à dimensão didático-pedagógica.

Os Tutores presenciais e a distância foram avaliados como bons mediadores do processo de ensino e aprendizagem, atuando no papel de docentes no Curso de Pedagogia junto aos educandos, esclarecendo dúvidas, estimulando-os a prosseguir e participando do processo de avaliação da aprendizagem. $\mathrm{Na}$ avaliação dessa categoria pode-se perceber que houve uma proximidade de opiniões quanto à liberdade de intervir junto aos alunos na realização dos trabalhos, autonomia no encaminhamento pedagógico das atividades propostas para disciplina e contribuição junto aos alunos na construção de um novo paradigma de educação na modalidade em EaD, o que foi considerado bom em três Polos, Colombo, Rio Negro e Palmeiras. Vale ressaltar que é importante na formação de professores no contexto EaD levá-los a desenvolver a consciência de co- 


\section{QUADRO I - AVALIAÇÃO DA CATEGORIA TUTORES}

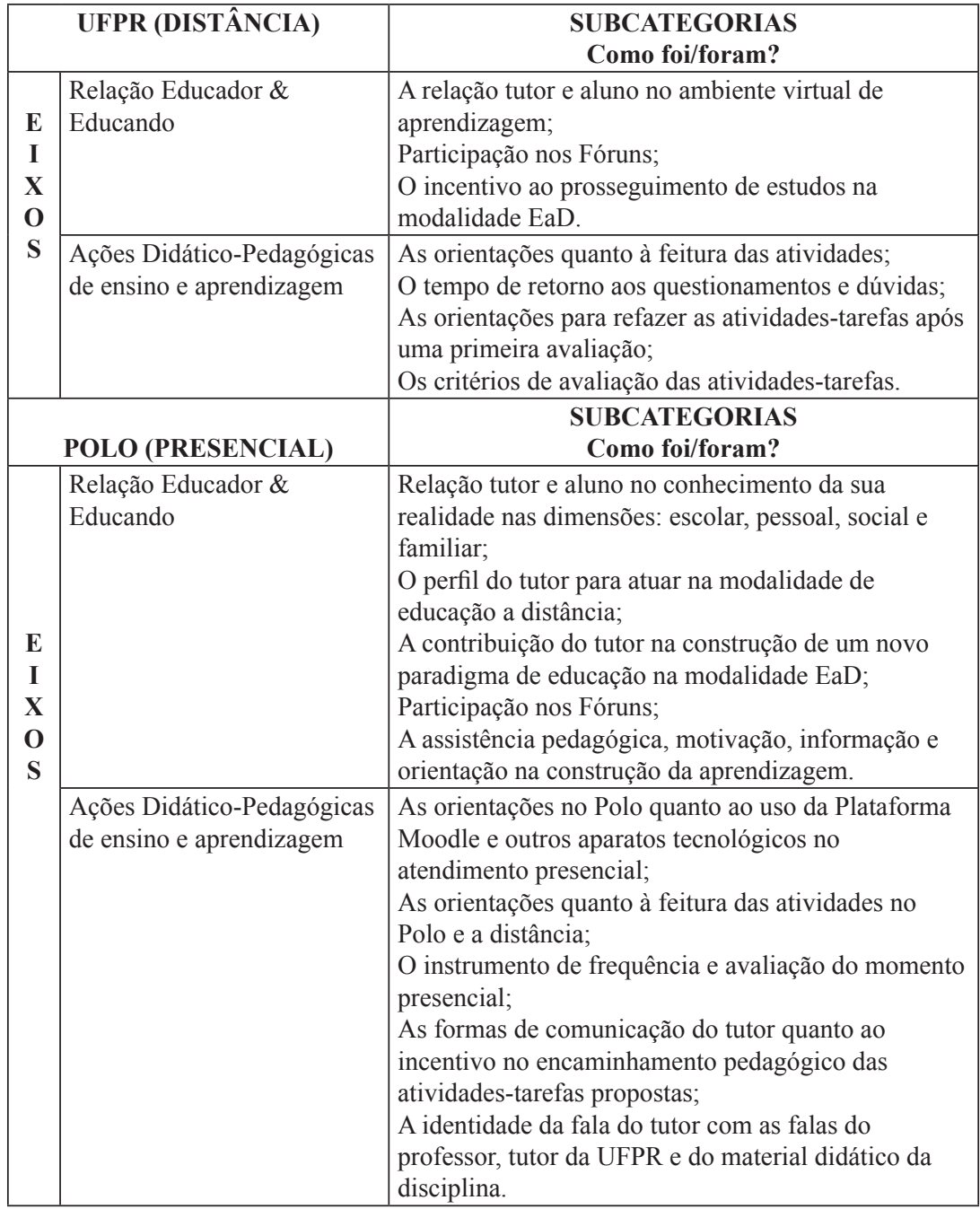

FONTE: As autoras (2012). 
nhecer o que já existe, bem como estar aberto a aprender, ensinar e pesquisar, para conhecer, para constatar, intervir, se educar e ser educado. (FREIRE, 1997, p. 32). Porém, isso não acontecia em um dos Polos, pois a tutoria foi avaliada como muito falha e sofrível, sendo constatado que a tutora era ausente, tinha três matrículas, sendo uma na rede estadual e duas na rede municipal, trabalhava os três turnos. Atendia os educandos aos sábados das $07 \mathrm{~h} 30$ às $19 \mathrm{~h} 00$, avaliado como tempo fictício, insuficiente.

Já em outro Polo o problema era a coordenadora local, que criava problemas com as tutoras selecionadas pela coordenação do curso da UFPR. Uma tutora selecionada tinha mestrado, foi excelente na avaliação dos licenciandos, da coordenação UFPR e dos tutores a distância, mas não permaneceu frente ao assédio da coordenação, que impedia que seu trabalho fosse desenvolvido a contento. Segundo Freire (1997, p. 38-39), essa postura denota uma pessoa que não pensa certo, pois, para ele, mesmo que "[...] se discorde do seu oponente não tem por que contra ele ou contra ela nutrir uma raiva desmedida, bem maior, às vezes, do que a razão mesma da discordância". Pode-se considerar, a partir da fala do mestre, que a postura dessa coordenadora de Polo era de discordância com todos que pudessem ameaçar sua autoridade, pois as relações dos tutores, com os educandos e coordenação da UFPR, buscavam juntos se produzirem, de forma que a gestão fosse participativa. Assim sendo, tudo que viesse do grupo era negado.

Os Tutores a distância, atendendo, corrigindo e avaliando as atividades programadas e postadas na plataforma, são responsáveis por esses processos junto aos professores conteudista e/ou formadores de cada disciplina e executores no processo avaliativo. Frente a isso ficou evidenciada a existência de conflitos hierárquicos quanto à atuação dos tutores, o que provocou tensões desde o início do curso, ambos " [...] com dificuldades na definição do desempenho das suas funções docentes, como também, com a articulação/desarticulação ao longo do processo de ensino-aprendizagem, principalmente no processo avaliativo" (OLIVEIRA, 2011. p. 105), responsabilidade do tutor a distância junto ao professor da disciplina.

Esse é o grande desafio da modalidade a distância, a mediação do trabalho do professor formador e dos tutores, na unicidade das falas pedagógicas e no detalhamento das atividades orientadas no Polo e via on-line. O tutor, ao acompanhar as aulas nos momentos presenciais, se inteira das explanações didáticas e instruções de trabalho para os alunos, que no decorrer da tutoria deve ter a mesma exigência do professor. É como se tivesse que pensar igual ao professor, se revestir de suas falas. Porém, quem sistematiza o processo avaliativo é o tutor a distância, na Plataforma Moodle do CIPEAD/UFPR.

A liberdade de intervenção avaliada como boa e entendida como autonomia de ação, segundo os licenciandos, acontecia juntamente com os tutores que parti- 
cipavam da construção de um novo paradigma de educação, rompendo barreiras de espaço, tempo e distância. Perceberam que o curso na modalidade EaD, em evolução, se tornava um caminho real de formação docente inicial, socialização de conhecimentos, de democratização dos bens culturais e técnicos produzidos coletivamente. Os licenciandos, se pautando nas explanações do professor e tirando suas dúvidas com os tutores, fizeram uma leitura crítica, e afirmaram na avaliação que os tutores a distância tinham mais afinidades de fala em relação aos professores das disciplinas que os tutores presenciais. Em contrapartida, os tutores presenciais conhecem a realidade dos educandos, segundo a avaliação, em todas as dimensões pessoal, social, familiar e escolar, e de certa forma isso contribuía nas situações de vida e tomada de consciência profissional.

Os tutores do Curso de Pedagogia - EaD, para a totalidade dos respondentes, atendem presencialmente e a distância, esclarecendo dúvidas via Plataforma Moodle, telefone, fax, correio ou e-mail e são responsáveis pela avaliação dos trabalhos realizados a distância, o que foi necessário para o desenvolvimento do trabalho pedagógico, avaliado como um bom entrosamento entre os protagonistas, em que alguns tutores tiveram o grau de excelência, pois tinham a mesma postura quanto às exigências e explanações do conteúdo e das atividades a serem realizadas. Os tutores, ao acompanharem os educandos nos momentos presenciais, se inteiravam do referencial teórico, das ideologias e das instruções de trabalho, procurando nortearem-se com posturas semelhantes a dos professores formadores.

\section{Considerações finais}

Os sujeitos respondentes desta avaliação foram autônomos ao saberem avaliar os papéis dos protagonistas e a si, destacando o real vivido e o ideal proposto. Agiram concebendo a EAD enquanto processo pedagógico, convivendo com diferentes realidades, organizando o trabalho pedagógico de acordo com as possibilidades de tempo e espaço de cada um, enfrentando os mitos e tabus frente a seus pares. Enfim, ao avaliarem e serem avaliados, construíram o perfil de aprender e ensinar, aprender à luz do paradigma do inacabamento, e se fazendo autônomos, cada um construindo a sua forma específica de aprendizagem, na interação, ou seja, com autonomia em aprender. Isto foi demonstrado na apresentação dos resultados das categorias avaliadas, repensadas e reconstruídas nos grupos. 
Compete, porém, a todos os envolvidos no processo educacional aprender a conhecer essa modalidade de ensinar e aprender, que não é nova, mas que ainda precisa se consolidar enquanto modalidade capaz de exercer um papel importante na disseminação do saber, com qualidade, de forma democrática e emancipatória, principalmente nos cursos de formação de professores, pois, na Universidade, muitos ainda têm posturas incrédulas a respeito da formação inicial no contexto da Educação a Distância.

\section{REFERÊNCIAS}

ÁLVARO MÉNDEZ, J. M. Avaliar para conhecer examinar para excluir. Porto Alegre, RS: Artmed, 2002.

ARETIO, L. G. La Educación a Distancia: de la teoria a la práctica. Barcelona: Ariel Educación, 2001.

BRASIL. Lei no 9.394/96. Lei de Diretrizes e Bases da Educação Nacional. Diário Oficial da União, Brasília, DF, 1996. Disponível em: <http://www.planalto.gov.br/ccivil_03/ leis/19394.htm>. Acesso em: 12 maio 2014.

BRASIL. Ministério da Educação e Cultura. Decreto $\mathrm{n}^{\circ}$ 5.622, de 19 de dezembro de 2005. Diário Oficial da União, Brasília, DF, 20 dez. 2005. Disponível em: <http://portal. mec.gov.br/seed/arquivos/pdf/dec_5622.pdf>. Acesso em: 10 maio 2013.

BRASIL. Ministério da Educação e Cultura. Universidade Aberta do Brasil - UAB. Decreto no 5.800, de 08 de junho de 2006. Diário Oficial da União, Brasília, DF, 2006. Disponível em: <http://www.mec.gov.br/>. Acesso em: 12 maio 2013.

BRASIL. Portaria Normativa MEC n ${ }^{\circ}$ 1.369, de 07 de dezembro de 2010. Dispõe sobre: Sistema Universidade Aberta do Brasil, para [...] e credenciar os polos de apoio presencial para a modalidade de Educação a Distância. Disponível em: <http://www.uab.ufmt.br/ uploads/ckfinder/userfiles/files/cartilha_orientacoes_uab.pdf $>$. Acesso em: 12 maio 2014.

CARDOSO, C. O corpo presente. In: RUBIM, A. C. et al. Comunicação e sociabilidade nas culturas contemporâneas. Petrópolis, RJ: Vozes, 1999.

ESTEBAN, M. T. (Org.). Avaliação no cotidiano escolar in "Avaliação Escolar: uma prática em busca de novos sentidos". 5. ed. Petrópolis, RJ: DP et Alli, 2008.

FREIRE, P. Educação como prática da liberdade. 17. ed. Rio de Janeiro: Paz e Terra, 1979.

FREIRE, P. Pedagogia do Oprimido. 13. ed. Rio de Janeiro: Paz e Terra, 1983. 
FREIRE, P. Pedagogia da autonomia: saberes necessários à prática educativa. Rio de Janeiro: Paz e Terra, 1997.

GIOLO, J. A Educação a Distância e a Formação de Professores. Educ. Soc., Campinas, v. 29, n. 105, p. 1211-1234, set./dez. 2008. Disponível em: <http:/www.scielo.br/pdf/ es/v29n105/v29n105a13.pdf>. Acesso em: 12 jun. 2013.

JÚNIOR, J. B. dos S.; ROCHA, A. P. da. Pesquisa em educação: reflexões metodológicas. In: SIMPÓSIO BRASILEIRO, 25.; CONGRESSO IBERO-AMERICANO DE POLÍTICA E ADMINISTRAÇÃO DA EDUCAÇÃO - ANPAE, 2., 2011, São Paulo. Anais... São Paulo, 2011. Disponível em: <http://www.anpae.org.br/simposio2011/cdrom2011/ PDFs/trabalhosCompletos/comunicacoesRelatos/0067.pdf>. Acesso em: 12 maio 2013.

OLIVEIRA, V. do C. de. Avaliação da aprendizagem na educação a distância online: um estudo sobre as concepções docentes. 143 f. Dissertação (Mestrado) - Programa de Pós-Graduação em Educação Matemática, Universidade Federal de Pernambuco, Pernambuco, CE, 2011. Disponível em: <http://repositorio.ufpe.br/handle/123456789/275>. Acesso em: 12 maio 2013.

PERRENOUD, P. A prática reflexiva no oficio de professor: profissionalização e reflexão pedagógica. Tradução: Cláudia Schilling. Porto Alegre, RS: Artmed, 1999.

PORTO, A. S.; NEVES, M. F.; MACHADO, M. J. Educação a Distância na Formação de Professores: Ranços e Avanços. In: CONGRESSO INTERNACIONAL DE EDUCAÇÃO A DISTÂNCIA - CIAED, 18., 2012, São Luís. Anais... São Luís, 2012. Disponível em: $<$ http://www.abed.org.br/congresso2012/anais/283f.pdf > . Acesso em: 08 maio 2013.

POSSARI, L. H. V. Educação à distância como processo semidiscursivo. In: PRETI, O. Educação a Distância: sobre discursos e práticas. Brasília, DF: Liber Livro, 2005.

PRETI, O. (Org.). Educação a distância: inícios e indícios de um percurso. Cuiabá, MT: UFMT - Nead/IE, 1996.

SANTOS, E.; SILVA, M. Avaliação da aprendizagem em educação online: fundamentos interfaces e dispositivos relatos de experiência. São Paulo: Edições Loyola, 2006. In: OLIVEIRA, V. do C. de. Avaliação da aprendizagem na educação a distância online: um estudo sobre as concepções docentes. 143 f. Dissertação (Mestrado) - Programa de Pós-Graduação em Educação Matemática, Universidade Federal de Pernambuco, Pernambuco, CE, 2011. Disponível em: <http://repositorio.ufpe.br/handle/123456789/275>. Acesso em: 12 maio 2013.

SANTOS, F. C. dos. UAB como Política Pública de Democratização do Ensino Superior via EaD. In: SIMPÓSIO BRASILEIRO, $25^{\circ}$ CONGRESSO IBERO-AMERICANO DE POLÍTICA E ADMINISTRAÇÃO DA EDUCAÇÃO - ANPAE, 2., 2011, São Paulo. Anais... São Paulo, 2011. Disponível em: <http://www.anpae.org.br/simposio2011/ cdrom2011/PDFs/trabalhosCompletos/comunicacoesRelatos/0184.pdf.>. Acesso em: 12 maio 2013. 
SANTOS, J. F. S. Avaliação no Ensino a Distância. Revista Ibero-Americana de Educação, v. 38, n. 4, 2006. Disponível em: <http://www.fe.unb.br/catedraunescoead/areas/menu/ publicacoes/artigos-sobre-tics-na-educacao/avaliacao-no-ensino-a-distancia/view $>$. Acesso em: 12 maio 2013.

SILVA, E. R. G. da et al. Gestão de polo de apoio presencial no sistema Universidade Aberta do Brasil: construindo referenciais de qualidade. Novas Tecnologias na Educação, CINTED-UFRGS, v. 8, n. 3, dez. 2010. Disponível em: <http://seer.ufrgs.br/renote/ article/viewFile/18086/10662>. Acesso em: 12 maio 2014.

SILVA, J. F.; HOFFMANN, J.; ESTEBAN, M. T. Práticas Avaliativas e aprendizagens significativas em diferentes áreas do currículo. Porto Alegre: Editora Mediação, 2006.

UNIVERSIDADE FEDERAL DO PARANÁ. Projeto Político Pedagógico do Curso de Pedagogia EaD - Magistério da Educação Infantil e anos iniciais do Ensino Fundamental. Curitiba, 2009.

VERSUTI, A. C. Qualidade do ensino a distância na percepção de coordenadores: resultados do estudo de caso sobre o curso para gestores da rede de ensino médio estadual do Estado de São Paulo. In: CONGRESSO DA ABED, 4., 2007, Campinas, SP. Anais... Campinas, SP: UNICAMP/UNICOC, 2007. Disponível em: <http://www.abed.org.br/ congresso2007/tc/4242007115754PM.pdf>. Acesso em: 03 mar. 2014.

Texto recebido em 13 de julho de 2015. Texto aprovado em 04 de agosto de 2015. 